\title{
ADENOID CYSTIC CARCINOMA OF THE LARYNX: AN UNIQUE PRESENTATION
}

\author{
Sheila Raman¹, Ranjit Rajan², Rajamma Rajan³
}

\section{HOW TO CITE THIS ARTICLE:}

Sheila Raman, Ranjit Rajan, Rajamma Rajan. "Adenoid Cystic Carcinoma of the Larynx: A Unique Presentation". Journal of Evolution of Medical and Dental Sciences 2014; Vol. 3, Issue 22, June 02; Page: 5950-5953, DOI: $10.14260 /$ jemds/2014/2687

CASE REPORT: A 40 year male patient presented to us with the history of having coughed out moderate quantities of blood on two occasions during the preceding week. During one episode he had coughed out a piece of tissue as well. The hemoptysis subsided spontaneously. On further questioning he reported occasional breathing difficulty on exertion, mild intermittent change in voice and minimal discomfort in the throat during the previous one and a half month. He gave no history of evening rise of temperature, chest pain, and loss of weight or appetite. He was not habituated to smoking or alcohol consumption.

General examination and systemic examination including chest and abdominal examination was unremarkable. There was no stridor. Indirect laryngoscopic examination revealed a congested and thickened right vocal cord. Both vocal cords were found to move normally. No ulcer or mass was visible in the larynx or pharynx. Neck nodes were not palpable.

During one of the episodes of hemoptysis he had coughed out a piece of tissue. This had been sent for histological examination by the doctor he had consulted initially for hemoptysis and it was reported as adenoid cystic carcinoma.

The chest X- ray, urinalysis and routine blood tests were normal. Tomogram of the larynx showed a soft tissue shadow in the right subglottis, direct laryngoscopy and bronchoscopy revealed a pinkish, sessile mass in the right half of the subglottis with an irregular surface. There was no other lesion in the tracheobronchial tree.

He underwent total laryngectomy with right hemithyroidectomy. The upper tracheal rings were resected with the larynx. No enlargement of neck nodes was noticed during surgery.

The resected specimen showed a $1.5 \times 1.5 \mathrm{~cm}$ sized pink, fleshy, sessile mass in the right subglottis extending from $1 \mathrm{~cm}$ below the free margin of the vocal cord to the second tracheal ring (Fig. 1). Histopathological examination of the excised specimen showed adenoid cystic carcinoma (Fig. 2). The patient had an uneventful postoperative recovery. Later on, he developed tracheostomal stenosis for which he underwent stomoplasty. Seven months after the initial surgery he underwent successful surgical voice restoration by secondary tracheo-oesophageal puncture and Blom-Singer's voice prosthesis insertion.

The patient was disease free 32 months after surgery, when last seen.

DISCUSSION: Adenoid cystic carcinoma of the larynx is a rare entity. ${ }^{1-10}$ They arise from seromucinous glands and minor salivary tissue in the laryngeal mucosa. ${ }^{2}$ The greatest concentration of these structures in the larynx is in the supraglottis, on the false cords and just inferior to the anterior commissure respectively.2,3 
This explains the propensity of these tumors to occur in the subglottis and supraglottis. Approximately half to two thirds of them arise in the subglottis.2, 3, 5 Subglottic lesions tend to be more advanced at presentation. ${ }^{4}$

Peak incidence is in the fifth decade, with no sex predilection. ${ }^{1,4}$ In addition to the usual change in voice and airway obstruction, pain may be a prominent feature.2,4-6 This has been said to be due to the well-known propensity of these neoplasms to spread perineurally.4,7 However, the presentation with hemoptysis as the presenting complaint, as in our patient, is very unusual for laryngeal neoplasms, especially of this variety, as these neoplasms are known to grow submucosally with a tendency to produce non-ulcerated masses.1,4

This may lead one to miss these neoplasms, more so in the subglottis which is a difficult area to be visualized. As was seen in the present case, most of the patients do not have palpable neck nodes as initial presentations. ${ }^{4,5}$

The treatment protocol for these neoplasms has not been standardized owing to their rarity as well as their tendency to run a protracted clinical course with multiple and late recurrences. The treatment widely advocated for the primary lesion is radical excision. ${ }^{4,6-8}$ Opinion is divided regarding the advisability of conservation laryngeal surgery for these neoplasm.1,6-8 Because of the high propensity for submucosa spread and perineural and lymphovascular invasions, total laryngectomy is usually recommended. ${ }^{7}$

Neck node metastasis in adenoid cystic carcinoma is uncommon at clinical presentation. Neck dissection is reserved for patients with clinically apparent lymphadenopathy. 1,8 Soma advocate combination therapy with surgical resection and radiotherapy as more effective in achieving tumor remission than is surgical resection alone. $1,5,8$

Disease recurs in most patients, often at a distant site and predominantly in the lungs. 1, 2, 6,7

However, this tumor shows a slow growth rate, with many patients surviving for a prolonged period of time with the disease. ${ }^{1}$

Adenoid cystic carcinoma has a tendency to run a prolonged course and a five- year follow-up is meaningless in assessing cure..$^{3-5}$

\section{REFERENCES:}

1. Moukarbel R V, Goldstein D P, O’Sullivan P, Gullane P J, Brown D H, Wang L, Irish J C Adenoid cystic carcinoma of the larynx: a 40 year experience. Head Neck. Jul.2008;30 (7):919-24.

2. Andre’Del Negro, Edson Ichihara, Alfio Jose Tincani, Albina Altemani, Antonio Santos Martins. Laryngeal adenoid cystic carcinoma: case report. Sao Paulo Med. J. 2008; Vol.125 no.5.

3. Ganly I, Patel SG, Coleman M, et al. Malignant minor salivary gland tumours of the larynx. Arch Otolaryngol Head Neck Surgery. Jul. 2006., 132(7):767-70.

4. Alvi S, IV Amazie A, Calcaterra TC, Blackwell K E. Glandular carcinoma of the larynx: the UCLA experience. Ann Otol Rhino Laryngol. May. 1999;108 (5)485-9.

5. Donovan D T, Conley J. Adenoid cystic carcinoma of the subglossic region. Ann Otol Rhino Laryngol. Sep- Oct. 1983; 92 (5):491-5.

6. E Zvrko, M Golubovic. Laryngeal Adenoid cystic carcinoma. Acta Otorhinolaryngol Ital.Oct.1999; 29 (5):279-282.

7. Batsakis J G. Tumours of the Head and Neck. Clinical and Pathological Considerations. Baltimore: The William and Wilkins Co. 1979. 


\section{CASE REPORT}

8. Houle J.A, Joseph P, Batsakis J.G. Primary Adenoidcarcinoma of the larynx. J Laryngol Otol.1979; 90:1159-1163.

9. Olofsson J, Van Nostrand A.W.P. Adenoid Cystic Carcinoma of the larynx: A report of four cases and review of the literature. Cancer. 1977; 40: 1307-1313.

10. Whicker J H, Neel H B, Weiland L H Devine K D. Adenoid carcinoma of the larynx. Ann Otol Rhinol Laryngol 1974; 83:487-490.

11. Ganly I, Patel S G, Colman M, Ghossein R, Carlson D, Shah J P. Malignant minor salivary gland tumours of the larynx. Arch Otolaryngol Head Neck Surg.July.2006;132 (7):767-70.

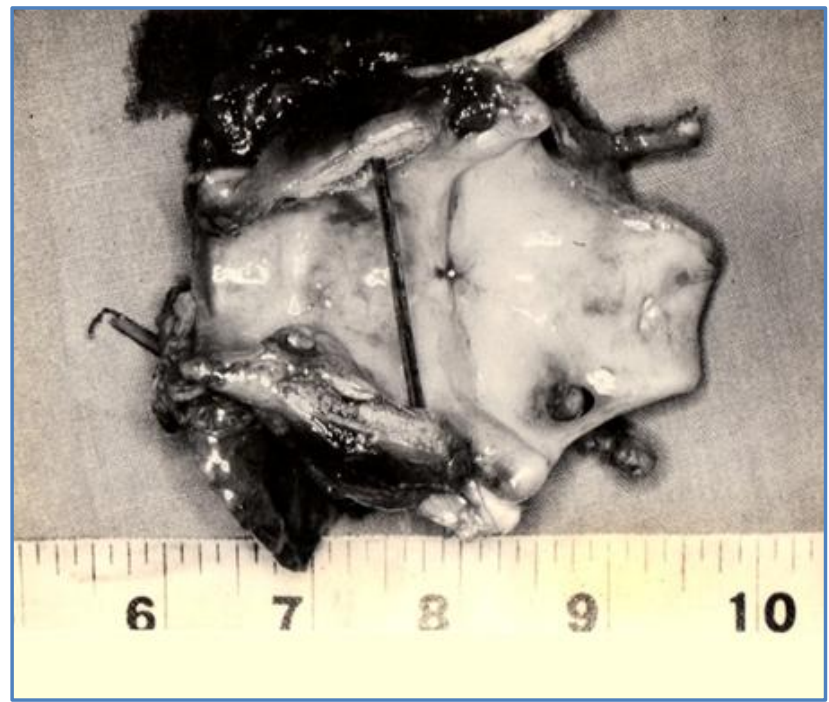

Fig. 1: Total laryngectomy specimen split open to show the neoplasm in the right subglottis

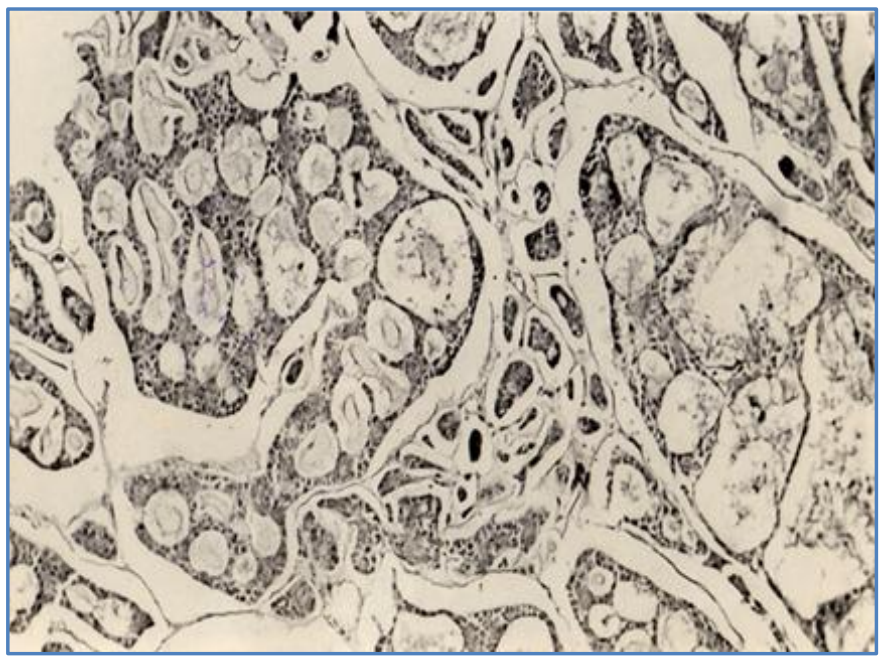

Fig. 2: Photomicrograph showing adenoid cystic carcinoma with typical cribriform pattern (H and E staining, magnification x 250) 


\section{CASE REPORT}

\section{AUTHORS:}

1. Sheila Raman

2. Ranjit Rajan

3. Rajamma Rajan

\section{PARTICULARS OF CONTRIBUTORS:}

1. Associate Professor, Department of ENT, Pariyaram Medical College, Kannur, Kerala.

2. Professor, Department of ENT, Amala Institute of Medical Sciences, Thrissur, Kerala.

3. ENT Consultant, Formerly Professor and HOD, Department of ENT, Kasturba Medical College, Manipal, Karnataka.

\section{NAME ADDRESS EMAIL ID OF THE}

\section{CORRESPONDING AUTHOR:}

Dr. Sheila Raman,

\#202, Keshava Apartment,

Nehru Avenue, Lalbaugh,

Mangalore-575003, Karnataka.

Email: sheelaent@yahoo.com

Date of Submission: 28/04/2014.

Date of Peer Review: 29/04/2014.

Date of Acceptance: 23/05/2014.

Date of Publishing: 27/06/2014. 